\title{
Genotyping and sero-virological characterisation of hepatitis B virus-infected blood donors in Central Eritrea
}

\section{Mohammed Elfatih Hamida ( $\sim$ mohelfatih77@gmail.com )}

Orotta College of Medicine and Health Sciences, Department of Microbiology https://orcid.org/00000002-5337-399X

\section{Saud Mohammed Raja}

Orotta College of Medicine and Health Sciences, Department of Internal Medicine

\section{Yodahi Petros}

National Animal and Plant Health Laboratory, Unit of Molecular Biology

\section{Isam Mohammed Elkhidir}

University of Khartoum, Faculty of Medicine, Department of Microbiology

\section{Munir Wahab}

National Animal and Plant Health Laboratory, Unit of Molecular Biology

\section{Oliver Okoth Achila}

Department of Clinical Laboratory Sciences, Asmara College of Health Science (ACHS)

\section{Freweini Tekle}

Ministry of Health, National Health Laboratory

\section{Isayas Yohannes Berhane}

Data Management Unit, National Blood Transfusion Service (NBTS)

\section{Research Article}

Keywords: hepatitis B virus, blood donors, Eritrea, genotype, HBsAg, HBcAb, ELISA, genotypes, multiplexnested PCR

Posted Date: May 24th, 2021

DOI: https://doi.org/10.21203/rs.3.rs-555317/v1

License: () (i) This work is licensed under a Creative Commons Attribution 4.0 International License. Read Full License 


\section{Abstract}

\section{Aim}

To determine serological markers and genotypes profiles of HBV isolates in Central Eritrea.

\section{Materials \& methods}

A total of $191 \mathrm{HBsAg}$ sero-positive samples were randomly selected for the study from 23,232 screened blood donors from 2015 to 2017. Enzyme-linked immunosorbent assay was used to perform HBV serological markers screening, while genotypes were determined using type-specific primer-based multiplex-nested PCR.

\section{Results}

The median age of infected blood donors was $28.9 \pm 10.26$ years. Of $191 \mathrm{HBsAg}$ reactive serum samples, 77.5\% (148/191) were sero-positive for HBcAb-total, among which 99.3\% (147/148) and 0.7\% (1/148) were sero-positive for HBsAg and HBsAb, respectively. Interestingly, among $147 \mathrm{HBcAb}$-total/HBsAg reactive samples, 16 (10.9\%) and 131 (77.9\%) were sero-positive for HBeAg and HBeAb, respectively. For genotyping, 73 HBV isolates were successfully amplified and genotyped, with 59 (80.8\%) had a monogenotype and 14 (19.2\%) had a mixed-genotype infection. Among HBV isolates with mono-genotypes: 39 (53.4\%) D; 10 (13.7\%) E; 6 (8.2\%) A and 4 (5.5\%) C. While five mixed-genotypes comprised: 6 (8.2\%) C/D; 3 (4.1\%) C/D/E; 2 (2.7\%) each with genotype A/D and D/E; and 1 (1.4\%) genotype B/D.

\section{Conclusion}

HBV genotype D is the predominant genotype, either as a HBV mono- or mixed-genotype infection, among blood donors in Eritrea.

\section{Introduction}

Hepatitis B virus (HBV) is a global epidemic and chronically affecting more than 250 million people, among which 65 million live in Africa [1, 2]. Globally, the mortality rate of HBV is alarmingly increased, with 500,000 to 1.2 million deaths reported annually [3,4]. A substantial proportion of this figure (87890 deaths) are is contributed by Sub-Saharan African (SSA) [2]. SSA is a HBV infection endemic region, with an intermediate to high prevalence [5]. The median overall risk of HBV transfusion-transmission in SSA is 4.3 per 1,000 units of blood [6]. Eritrea is an East African multi-ethnic country, where HBV infection remains as one of the major public health burdens. Previous studies conducted among Eritrean blood donors have indicated that the positivity rates of HBsAg, which is the widely accepted HBV serological marker, are intermediate endemicity, between $2.0 \%$ [7] to $5 \%$ [8]. 
Generally, HBV belongs to the Hepadnaviridae family and contains a partially double-stranded circular DNA genome, approximately $3.2 \mathrm{~kb}$ length. It presents four partially overlapping open reading frames encoding polymerase, surface core and $X$ proteins [9-11]. To date, multiple techniques for genotype characterisation are available, including

Different HBV genotypes have different geographic distributions, with genotypes $A, D$ and $E$ are particularly distributed in diverse geographical locale of SSA covering Eastern Africa, Central Africa, Southern Africa and Western Africa. However, information on genotype prevalence in many African countries is still scarce [2]. It has been widely reported that genotype $A$ is found predominantly distributed in North-Western Europe and North America compared to genotypes B and C are observed mainly in Asia. While genotype $D$ is discovered to be highly prevalent in Mediterranean regions [15]. Genotype $F$ is localised mainly in South and Central America [16], and USA and France residents is prevailed with [17], while genotype $\mathrm{H}$ is found in Central America [18]. Lastly, genotypes I and $\mathrm{J}$ are found predominantly observed in Laos and Vietnam, and Japan, respectively [19].

As previously described, the lack of reliable health information or statistics on HBV prevalence or the frequency of specific genotypes has imposed a limit on public health efforts. In Eritrea, for instance, genotyping and sero-virological characterisation data is extremely hard to gather. Thus, this situation presents an urgent need to identify the genotypes profile among HBV patients as such information of genotypes prevailing in Eritrea is important in treatment management and prognosis. In this study, we identified and characterised HBV isolates among infected blood donors using a panel of serological markers, followed by evaluated genetic diversity using genotyping. We demonstrated $191 \mathrm{HBsAg}$ infected blood donors were sero-positive for Hepatitis B core antibody-total (HBcAb)-total, among which Hepatitis $B$ envelop antibody ( $\mathrm{HBeAb}$ ) contributed predominantly compared to Hepatitis B envelop antigen (HBeAg). Furthermore, we identified that four mono-genotypes and five mixed-genotypes in tested HBV isolates, with genotype $D$ was prevailed in both groups. Our results indicate that genotype $D$ is prevalent in HBV patients in Eritrea through which targeting it specifically may improve the clinical outcome.

\section{Materials And Methods}

\section{Study design and population}

This was a descriptive cross-sectional, laboratory based study conducted at National Blood Transfusion Service (NBTS) in Asmara, which is the capital city of Eritrea and serves about 20 referral hospitals [20]. It supplies blood and blood products and serves hospitals from six administrative regions (Zobas), including Maekel, Debub, Anseba, Gash-Barka, Semienawi Keiyh Bahri and Debubawi Keiyh Bahri.

A total of 23,232 infected blood donors were screened for serological status of HBV, Hepatitis C Virus (HCV), Human Immunodeficiency virus (HIV) and syphilis (Treponema pallidum) between January 2015 and December 2017 as part of routine blood donation requirement. Of 395 blood donors tested positive for HBsAg. Considering availability of resources 191 samples fulfilling a pre-set criteria (aged between 16 and 65 years and a body weight greater than $50 \mathrm{~kg}$ ), were randomly selected for inclusion in the study. 
HBsAg serum reactive samples were labelled with unique identifier code and stored at $-20^{\circ} \mathrm{C}$ until further investigation.

\section{Serological assays}

Enzyme Linked Immuno-Sorbent Assay [21] kits were used to screen for HBsAg (SD Standard Diagnostic, Republic of Korea), anti-HCV (SD Standard Diagnostic, Republic of Korea) and anti-T. pallidum (MEDDIFF, France). While HIV screening was done using an AccuDiag ${ }^{T M} \mathrm{HIV} 1 \& 2 \mathrm{Ag} / \mathrm{Ab}$ (Diagnostic

Automation/Cortez Diagnostic, California, USA). HBV-positive serum samples $(n=191)$ were re-tested for $\mathrm{HBcAb}$. Those with detectable HBcAb were further tested for hepatitis B surface antigen (HBsAg) and hepatitis B surface antibody (HBsAb) using ELISA kits (Fortress Diagnostics, UK). Only those with HBcAbtotal and HBsAg were then processed for DNA extraction and screened for other HBV serological markers, including HBeAg and HBeAb using ELISA kits (Fortress Diagnostics, UK).

\section{HBV DNA extraction}

HBV DNA was extracted from $200 \mu$ of serum using an Analytik Jena DNA mini-extraction kit (Analytik Jena, Germany) according to the manufacturer's instructions. The extracted DNA was then eluted in $60 \mu \mathrm{l}$ of pre-heat RNase-free water before storing at $-20^{\circ} \mathrm{C}$ until use.

Amplification of HBV S-gene for genotyping

A genotyping system based on multiplex-nested PCR with type-specific primers (Macrogen company, Seoul, Korea) was used. This process was undertaken for HBV genotypes A to F. Based on pre-S1 region in S genes of the HBV genome were targeted as described previously by Naito et al. (2001) [22]. The firstround PCR was performed using two universal outer primer pairs: P1 (sense) - 5'-

TCACCATATTCTTGGGAACAAGA-3') and S1-2 (antisense) - 5'CGAACCACTGAACAAATGGC-3'. For secondround PCR, B2 was used as the inner primer (sense) ( $5^{\prime}$ - GGCTCMAGTTCMGGAACAGT-3'), with a combination of antisense primers called mix $A$ for genotypes $A, B$ and $C$. The antisense primers used were: BA1R (genotype A specific, 68 bp) (5'-CTCGCGGAGATTGACGAGATGT-3'); BB1R (genotype B specific, 281bp) (5'-CAGGTTGGTGAGTGACTGGAGA-3'); BC1R (genotype C specific, 122bp) (5'GGTCCTAGGAATCCTGATGTTG-3'). While B2R was used as the inner primer (antisense) (5'GGAGGCGGATYTGCTGGCAA-3'), with a combination of antisense primers called mix $B$ for genotypes $D, E$ and $\mathrm{F}$. The antisense primers used were: BD1 (genotype D specific, $119 \mathrm{bp}$ ) (5'-GCCAACAAGGTAGGAGCT3'); BE1 (genotype E specific, 167 bp) (5'-CACCAGAAATCCAGATTGGGACCA-3'); BF1(genotype F specific, 97bp) (5'-GYTACGGTCCAGGGTTACCA-3').

The total volume of the reaction mixture was $20 \mu \mathrm{l}$. The mixture contained $16 \mu$ of nuclease-free water, 1 $\mu \mathrm{l}(10 \mathrm{pmol})$ each of P1 and S1-2 primers and $2 \mu \mathrm{l}$ of DNA sample, all of which were added to the tube of the ready mix containing $2.5 \mathrm{mM}$ dNTP mix, $2.5 \mathrm{U}$ Taq DNA Polymerase, $1 \mathrm{x}$ reaction buffer, and $1 \mathrm{x}$ gel loading buffer (iNtRON, Biotechnology, Korea). The mixture was centrifuged at 5,000 rpm for 15 seconds. The master cycler gradient (Eppendorf, Germany) was programmed as follows: incubation at $94^{\circ} \mathrm{C}$ for 5 
min, followed by 40 cycles of denaturation at $94^{\circ} \mathrm{C}$ for $1 \mathrm{~min}$, annealing at $60^{\circ} \mathrm{C}$ for 1 min and elongation at $72^{\circ} \mathrm{C}$ for $2 \mathrm{~min}$. The final elongation step was performed at $72^{\circ} \mathrm{C}$ for $5 \mathrm{~min}$.

Two second-round PCRs were performed for each first-round PCR product using either

$B 2$ and mix $A$ group for genotypes $A$ to $C$ or B2R and mix B group for genotypes $D$ to $F$. Firstly, 3-ml aliquot of the first PCR product was added to mix $A$ and mix $B$. The reaction mixture of mix A or $B$ (iNtRON, Biotechnology, Korea) contained $15 \mu \mathrm{l}$ of nuclease-free water and $2 \mu \mathrm{l}(10 \mathrm{pmol})$ of respective primers. Amplification conditions composed of 40 cycles of preheating at $95^{\circ} \mathrm{C}$ for $5 \mathrm{~min}$, followed by 20 cycles of amplification at $95^{\circ} \mathrm{C}$ for $20 \mathrm{~s}, 60^{\circ} \mathrm{C}$ for $20 \mathrm{~s}$ and $72^{\circ} \mathrm{C}$ for $30 \mathrm{~s}$ and an additional 20 cycles of $95^{\circ} \mathrm{C}$ for 20 $\mathrm{s}, 62^{\circ} \mathrm{C}$ for $20 \mathrm{~s}$ and $72^{\circ} \mathrm{C}$ for $30 \mathrm{~s}$.

Detection of HBV Genotypes

HBV genotypes for each serum sample were determined by identifying genotype-specific DNA bands. Two different second-round PCR products from one sample were separately electrophoresed for $1 \mathrm{~h}$ and 10 min at $100 \mathrm{~V}$ in $1.5 \%$ agarose gel D-1Low EEO (Eppendorf, Italy) stained with gel red (Biotium, USA). The gel was then observed and evaluated in UV light transilluminator (UVP, UK). The size of PCR products were estimated by comparing them to the migration pattern of a 50-bp DNA ladder (iNtRON, Biotechnology, Korea).

Data collection and analysis

The data of HBV infected blood donors were retrieved from the NBTS Delphyn Blood Bank Data Management version 7.6.10.0 database and transferred to Excel Spreadsheet (Microsoft Inc.). Meanwhile, the records of specific demographic information of all blood donors (age, sex, occupation, marital status, educational status, regions (Zobas) and blood group types (e.g., ABO and Rh) were retrieved with the assistance from the authorised staff of blood bank data center. Statistical analysis was analysed using the SPSS version 25.0 (IBM Corporation, Chicago, IL, USA). Basic statistics, such as percentages and mean \pm standard deviations (SD) were used to summarise the data, where appropriate. The baseline characteristics of blood donors were analysed using the Chi-square $\left(\chi^{2}\right)$ test or Fishers exact test (categorical variables). A two-tailed p-value less than 0.05 was considered statistically significant.

\section{Results}

\section{HBV detection and socio-demographic characteristics of 191 infected blood donors}

Of 23,232 blood donors were screened, ELISA analysis indicated that 395 (1.7\%), 352 (1.5\%), $100(0.4 \%)$ and $126(0.5 \%)$ were sero-positive for HBV, HCV, HIV and syphilis, respectively. Among 395 HBV seropositive samples, 191 samples were randomly selected and used for further laboratory analyses.

According to the socio-demographic information (Table 1), most HBV/HBsAg blood donors were single ( $\mathrm{n}$ $=123 ; 64.4 \%)$ and male $(n=141 ; 73.8 \%)$ compared to female $(n=50 ; 26.2 \%)$. The age of the blood donors was ranged from 16 to 60 years old, with the mean was $28.9 \pm 10.3$ years. Specifically, the aged 
less than 20 was the predominant group $(n=48 ; 25.1 \%)$ Besides, we found that $66 \%(n=34.6)$ of them were student, among which $50.8 \%(n=97)$ were from Zoba Maekel. A significantly number of them had blood group type $O(n=92 ; 48.2 \%)$ and Rh-positive $(n=175 ; 91.6 \%)$.

Table 1: Socio-demographic characteristics of the blood donors with HBV $(n=191)$ stratified by gender in Eritrea. 


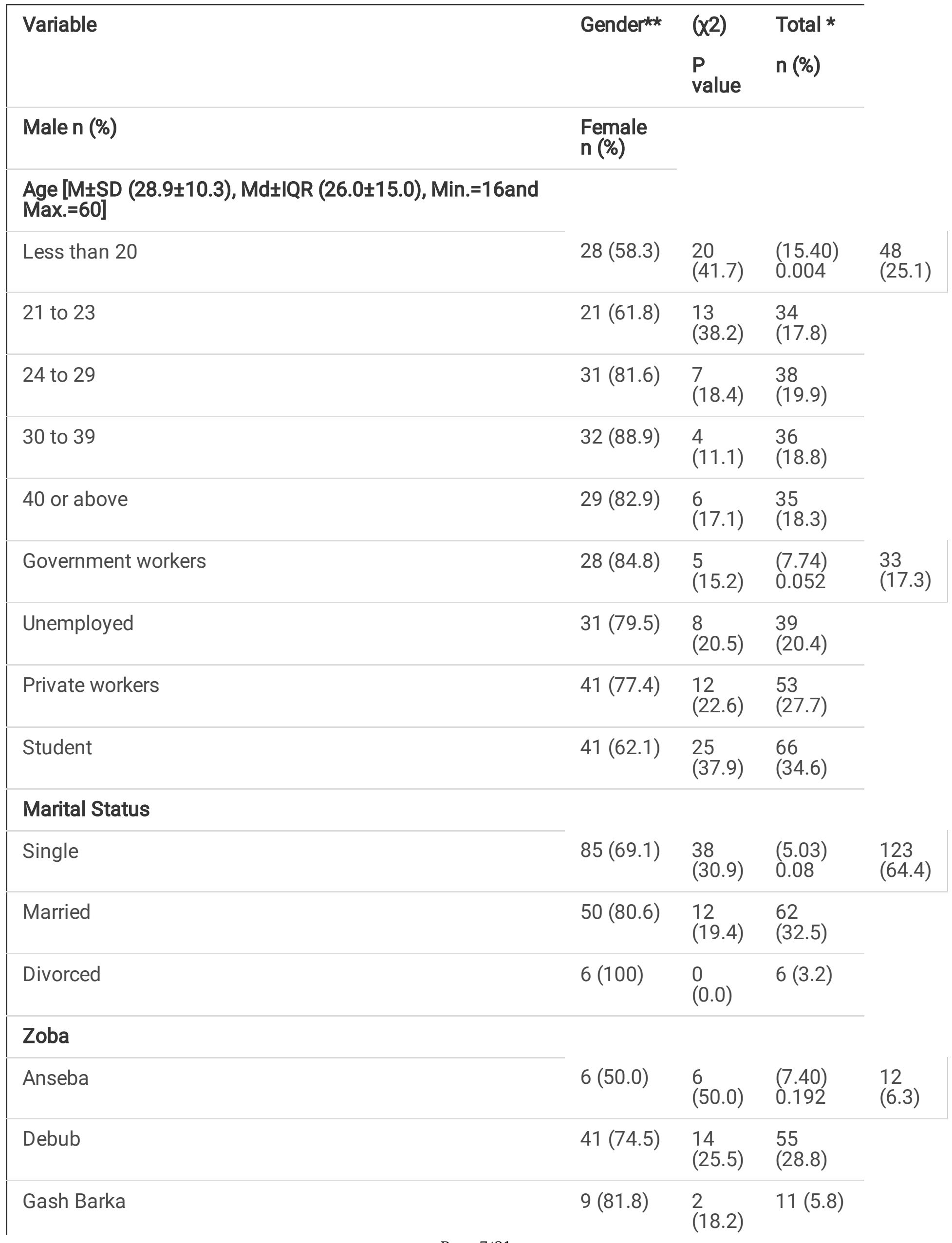




\begin{tabular}{lrll} 
Maekel & $70(72.2)$ & $\begin{array}{l}27 \\
(27.8)\end{array}$ & $\begin{array}{l}97 \\
(50.8)\end{array}$ \\
\hline Semienawi Keiyh Bahri & $12(92.3)$ & $\begin{array}{l}1 \\
(7.7)\end{array}$ & $13(6.8)$ \\
Debubawi Keiyh Bahri & $3(100)$ & $\begin{array}{l}0 \\
(0.0)\end{array}$ & $3(1.6)$
\end{tabular}

\section{Blood type}

\begin{tabular}{|c|c|c|c|}
\hline A & $30(76.2)$ & $\begin{array}{l}10 \\
(23.8)\end{array}$ & $\begin{array}{c}(2.30) \\
0.512\end{array}$ \\
\hline B & 35 (81.4) & $\begin{array}{l}8 \\
(18.6)\end{array}$ & $\begin{array}{l}43 \\
(22.5)\end{array}$ \\
\hline$A B$ & $10(71.4)$ & $\begin{array}{l}4 \\
(28.6)\end{array}$ & $14(7.3)$ \\
\hline 0 & $64(69.6)$ & $\begin{array}{l}28 \\
(30.4)\end{array}$ & $\begin{array}{l}92 \\
(48.2)\end{array}$ \\
\hline
\end{tabular}

\section{Rh type}

\begin{tabular}{lllll} 
Positive & 132 & 43 & $(2.79)$ & 175 \\
& $(75.4)$ & $(24.6)$ & 0.134 & $(91.6)$ \\
Negative & $9(56.3)$ & 7 & $16(8.4)$ \\
Total & & $(43.8)$ & \\
\cline { 2 - 4 } & & $\mathbf{1 4 1}$ & $\mathbf{5 0}$ & $\mathbf{1 9 1}$ \\
& $\mathbf{( 7 3 . 8 )}$ & $\mathbf{( 2 6 . 2 )}$ & $\mathbf{( 1 0 0 )}$
\end{tabular}

$\mathrm{M}=$ mean, $\mathrm{SD}=$ standard deviation, $\mathrm{Md}=$ median, $\mathrm{IQR}=$ interquartile range, Min. $=$ minimum and Max. $=$ maximum

*Percentage is computed from the row total,

**Percentage is computed from total HBV-infected blood donors.

HBV serological markers

The HBV serology test using ELISA kits showed that 77.5\% $(n=148)$ were reactive for HBcAb-total in 191 HBV sero-positive samples. These 148 serum samples we then tested for HBsAg. Interestingly, 147 serum samples (99.3\%) were for HBsAg reactive and one serum sample (0.7\%) was HBsAg non-reactive. The additional serology test for HBeAb and HBeAg was done on $147 \mathrm{HBcAb}$-total/HBsAg sero-positive samples. HBeAb were reactive in 113 samples $(77.9 \%)$, and 16 samples $(10.9 \%)$ were reactive for $\mathrm{HBeAg}$. Only 18 samples were non-reactive for both HBeAb and HBeAg. Additional information on the analysis of HBcAb-total/HBsAg-positive $(n=147)$ samples is summarised in Figure 1.

HBV genotype 
To identify the genotype profile of $147 \mathrm{HBcAb}$-total/HBsAg sero-positive samples, their DNA was detected and genotyped. Only HBV DNA from 73 samples (49.7\%) were detected successfully, while others had a very low or undetectable levels. Among positive HBV DNA samples, 55 samples (75.3\%) were HBeAb positive and only $10(13.7 \%)$ were HBeAg positive. HBV genotypes analysis was summarised in Table 2. The genotyping results indicated that 59 samples (80.8\%) were detected with mono-HBV genotype infection compared with 14 samples (19.2\%) had mixed-HBV genotypes.

The results further showed that the age of the extracted HBV DNA from 73 infected blood donors was ranged from 19 to 31 years old. The mean age was $30.01 \pm 10.6$ years, with 51 males $(69.9 \%)$ and 22 females (30.1\%). Four mono-HBV genotypes (e.g., A, B, D and E) and five mixed-HBV genotypes (e.g., A/D, $B / D, C / D, D / E$ and $C / D / E)$ were detected. Among mono-HBV genotypes, genotype $D(n=39 ; 53.4 \%)$ was the predominant circulating genotype, followed by genotype $E(n=10 ; 13.7 \%)$ (Figure 2), genotype $A(n=$ $6,8.2 \%)$ and genotype $C(n=4 ; 5.5 \%)$. Six mixed-HBV genotypes detected were genotype $C / D(n=6 ; 8.2 \%)$ (Figure 3) contributed the highest number, followed by genotype $C / D / E(n=3 ; 4.1 \%)$, genotype $A / D$ and genotype $D / E$ (each with $n=2 ; 2.7 \%)$ and genotype $B / D(n=1 ; 1.4 \%)$. The age of these groups was ranged from 25 to 33 years old.

Table 2: Distribution of genotypes among 73 HBV DNA-positive blood donors in Eritrea. 


\begin{tabular}{|c|c|c|c|c|c|c|}
\hline Variable & $\begin{array}{l}\mathrm{n} \\
(\%)\end{array}$ & $\begin{array}{l}\text { Age } \\
(M \pm S D)\end{array}$ & $\begin{array}{l}\text { HBeAb } \\
\text { Positive } \\
\text { (\%) }\end{array}$ & $\begin{array}{l}\mathrm{HBeAg} \\
\text { Positive } \\
\text { (\%) }\end{array}$ & Gender & \\
\hline Male & Female & & & & & \\
\hline n (\%) & n (\%) & & & & & \\
\hline \multicolumn{7}{|l|}{ HBV mono-genotype } \\
\hline Genotype A & $6(8.2)$ & $29.2 \pm 8.1$ & $6(10.9)$ & 0 & $5(9.8)$ & $\begin{array}{l}1 \\
(4.5)\end{array}$ \\
\hline Genotype C & $4(5.5)$ & $29.3 \pm 10.3$ & $2(3.6)$ & 0 & $3(5.9)$ & $\begin{array}{l}1 \\
(4.5)\end{array}$ \\
\hline Genotype D & $\begin{array}{l}39 \\
(53.4)\end{array}$ & $31.2 \pm 10.4$ & $\begin{array}{l}29 \\
(52.7)\end{array}$ & $6(8.2)$ & $\begin{array}{l}25 \\
(49.0)\end{array}$ & $\begin{array}{l}14 \\
(63.6)\end{array}$ \\
\hline Genotype E & $\begin{array}{l}10 \\
(13.7)\end{array}$ & $19.9 \pm 11.8$ & $\begin{array}{l}10 \\
(18.2)\end{array}$ & 0 & $\begin{array}{l}6 \\
(11.8)\end{array}$ & $\begin{array}{l}4 \\
(18.2)\end{array}$ \\
\hline \multicolumn{7}{|l|}{ HBV mixed genotypes } \\
\hline Genotype A/D & $2(2.7)$ & $33.5 \pm 17.7$ & $2(3.6)$ & 0 & $2(3.9)$ & $\begin{array}{l}0 \\
(0.0)\end{array}$ \\
\hline Genotype B/D & $1(1.4)$ & - & $1(1.8)$ & 0 & $0(0.0)$ & $\begin{array}{l}1 \\
(4.5)\end{array}$ \\
\hline Genotype C/D & $6(8.2)$ & $28.5 \pm 15.9$ & $3(5.5)$ & $1(1.4)$ & $\begin{array}{l}6 \\
(11.8)\end{array}$ & $\begin{array}{l}0 \\
(0.0)\end{array}$ \\
\hline Genotype D/E & $2(2.7)$ & $33.5 \pm 7.8$ & 0 & $2(2.7)$ & $2(3.9)$ & $\begin{array}{l}0 \\
(0.0)\end{array}$ \\
\hline Genotype C/D/E & $3(4.1)$ & $25.3 \pm 7.8$ & $2(3.6)$ & $1(1.4)$ & $2(3.9)$ & $\begin{array}{l}1 \\
(4.5)\end{array}$ \\
\hline Total & $\begin{array}{l}73 \\
(100)\end{array}$ & $30.0 \pm 10.6$ & $\begin{array}{l}55 \\
(75.3)\end{array}$ & $\begin{array}{l}10 \\
(13.7)\end{array}$ & $\begin{array}{l}51 \\
(69.9)\end{array}$ & $\begin{array}{l}22 \\
(30.1)\end{array}$ \\
\hline $\begin{array}{l}\text { (-): Mean and SD cannot be } \\
\text { computed because only one } \\
\text { person had genotype B/D. }\end{array}$ & & & & & & \\
\hline
\end{tabular}

\section{Geographical distribution of genotypes among 73 HBV DNA-positive blood donors in Eritrea}

We then compared geographical distribution of genotypes among 73 HBV DNA-positive blood donors. Based on the results shown in Table 3, 35 of them (47.9\%) resided in Zoba Maekel, followed by Debub ( $\mathrm{n}$ $=23 ; 31.5 \%)$, Semienawi Keiyh Bahri $(n=6 ; 8.2 \%)$, Gash Barka $(n=5 ; 6.8 \%)$ and Anseba $(n=4 ; 5.5 \%)$, with no contribution from Zoba Debubawi Keiyh Bahri. In comparison, genotype D was the predominant mono- 
HBV genotype, from which the majority resided in Maekel $(n=15)$ and Debub $(n=14)$. Among mixed-HBV genotypes from $14 \mathrm{HBV}$ DNA, six were detected for genotype $C / D$, which were distributed equally in Maekel, Debub and Semienawi Keiyh Bahri. While no HBV DNA extracted from blood donors resided in Anseba and Debubawi Keiyh Bahri. Besides, it was found that all five mixed-HBV genotypes contained genotype $D$. Insignificant difference of isolated genotype among six Zoba regions $(P=079)$.

Table 3: Distribution of different mono- and mixed HBV genotypes isolated among 73 HBV DNA-positive blood donors across six Zoba regions in Eritrea.

\begin{tabular}{|c|c|c|c|c|c|c|c|}
\hline HBV Genotype & $\begin{array}{l}\text { Zoba } \\
(p=0.79)\end{array}$ & $\mathbf{N}$ & & & & & \\
\hline Anseba & Debub & $\begin{array}{l}\text { Gash } \\
\text { Barka }\end{array}$ & Maekel & SKB* & DKB** & & \\
\hline$(n=4), 5.5 \%$ & $\begin{array}{l}(n= \\
23), 31.5 \%\end{array}$ & $\begin{array}{l}(n= \\
5), 6.8 \%\end{array}$ & $\begin{array}{l}(n= \\
35), 47.9 \%\end{array}$ & $\begin{array}{l}(n= \\
6), 8.2 \%\end{array}$ & $\begin{array}{l}(n= \\
0), \%\end{array}$ & & \\
\hline \multicolumn{8}{|l|}{ HBV mono- genotype } \\
\hline Genotype A & $0(0.0)$ & $3(13.0)$ & 0 & $3(8.6)$ & 0 & 0 & 6 \\
\hline Genotype C & $0(0.0)$ & $2(8.7)$ & 0 & $2(5.7)$ & 0 & 0 & 4 \\
\hline Genotype D & $3(75.5)$ & $\begin{array}{l}14 \\
(60.9)\end{array}$ & $3(60.0)$ & $\begin{array}{l}15 \\
(42.9)\end{array}$ & $\begin{array}{l}4 \\
(66.7)\end{array}$ & 0 & 39 \\
\hline Genotype E & $1(25.0)$ & $1(4.3)$ & $1(20.0)$ & $\begin{array}{l}7 \\
(20.0)\end{array}$ & 0 & 0 & 10 \\
\hline \multicolumn{8}{|l|}{ HBV mixed genotypes } \\
\hline Genotype A/D & 0 & 0 & 0 & $2(5.7)$ & 0 & 0 & 2 \\
\hline Genotype B/D & 0 & $1(4.3)$ & 0 & 0 & 0 & 0 & 1 \\
\hline Genotype C/D & 0 & $2(8.7)$ & 0 & $2(5.7)$ & $\begin{array}{l}2 \\
(33.3)\end{array}$ & 0 & 6 \\
\hline Genotype D/E & 0 & 0 & 0 & $2(5.7)$ & 0 & 0 & 2 \\
\hline Genotype C/D/E & 0 & 0 & $1(20.0)$ & $2(5.7)$ & 0 & 0 & 3 \\
\hline \multicolumn{8}{|l|}{$\begin{array}{l}\text { *SKB }=\text { Semienawi Keiyh Bahri } \\
\text { (Northern Red Sea) }\end{array}$} \\
\hline $\begin{array}{l}* * D K B=\text { Debubawi Keiyh Bahri } \\
\text { (Southern Red Sea) }\end{array}$ & & & & & & & \\
\hline
\end{tabular}

\section{Discussion}

HBV infection affects millions of people worldwide, cutting across gender and all ages [23]. The current study demonstrated the prevalence of serological markers and genotype distribution for the first time 
among HBV-infected blood donors in Eritrea. In the present study, 191 blood donors with HBsAg-positive with the mean age of $28.9 \pm 10.3$ years were included. Similarly, the mean age of the first-time blood donor with HBsAg-positive in a study conducted in Gabon, Central Africa was $28.5 \pm 7.8$ years [23], and $33.4 \pm 8.3$ years for Egyptian blood donors [24]. Our study showed that majority HBV-infected blood donors were students (25.1\%) with aged below 20 (34.6\%). This age group might be preferable for blood transfusion due to having good fitness, their higher HBV prevalence may be linked to their lifestyle and unique behavioural characteristics like acquiring piercings or tattoos. Overall, the socio-professional categories of blood donors in this study coincide with the earlier studies $[23,25]$.

It has been widely reported that knowledge about serological markers of HBV patients plays an important role in characterising the nature of the disease. In endemic regions, approximately one-third of the population have a previous HBV infection, as indicated by an isolated HBcAb serology [26]. In this study, 99.3\% of the HBV-infected blood donors were in chronic phase with positivity for both HBcAb-total and $\mathrm{HBsAg}$, suggesting that the proportion of them exhibiting previous exposure or recovery from HBV infection (tested positive for HBsAb) was low (0.7\%). These findings are in line with a recent study in Eritrea among pregnant women where only $14.2 \%$ tested positive for HBsAb [27].

In a separate analysis of this study, HBeAg positivity among 147 blood donors was $10.9 \%$, and $76.9 \%$ were $\mathrm{HBeAb}$-positive. Nonetheless, HBeAg seropositivity for HBV-infected blood donors in our study was lower than those reported from Ethiopia [28], Egypt [29] and Tanzania [30]. HBeAg, a marker of active viral replication and higher infectiousness, is associated with higher risk for liver cirrhosis and hepatocellular carcinoma [31]. Sero-conversion to HBeAb frequently concurs with a considerable decline of viral DNA replication rate and clinical status [32].The higher prevalence of HBeAb in $147 \mathrm{HBcAb}$-total/HBsAg blood donors is consistent with a previous study conducted among pregnant women in Eritrea [27] . A similar pattern has also been observed in other regions like Egypt and Saudi Arabia [29, 33].

Furthermore, this study also evaluated the HBV genotypes among blood donors in Eritrea. We focused on six major HBV genotypes (A-F) using multiplex-nested PCR with type-specific primers. This method appears to generate higher sensitivity for detecting mixed genotypes, and it is simple and cost-effective for large population studies with more than $90 \%$ accuracy rate [14]. Of $147 \mathrm{HBcAb}$-total/HBsAg-positive samples, $49.7 \%(n=73)$ were shown to have HBV DNA. This percentage is nearly similar to that obtained in an earlier study conducted in Angola (53\%) that genotype E was circulating [34] and lower than those similar studies in Iraq, Côte d'Ivoire and India [35-37]. This observation may be explained due to the differences in methodologies, viral loads and HBeAg positivity rates. Additionally, $80.8 \%$ of 73 HBV DNApositive blood donors had mono-HBV genotype infection, and the remaining $19.2 \%$ had mixed-HBV genotypes. In fact, a higher prevalence of mono-HBV genotypes has also reported in other studies [38-40]. Our result also found a disparity in the regional distribution of HBV DNA-positive blood donors that most of them resided in Zoba Maekel (47.9\%) registering the highest frequency compared to other Zoba regions. This condition is probably due to that NBTS is located in Zoba Maekel, which is the place of having the highest number of blood donors. 
In terms of HBV genotypes, our results identified that genotype $D$, irrespective of the occurrence of mixed or single infection, was the predominant circulating genotype, followed by genotypes $E, A, C / D, C, C / D / E$, $A / D, D / E$ and $B / D$. Some investigators have also suggested that patient's fulminant hepatitis is more frequent in patients with genotype $D$ infection [41], with higher HBeAg positivity seen in patients infected with genotype $D$ adds credence to this assertion. Interestingly, HBV mono-genotype infection was shown to dominate over mixed genotype infection that opposed to a study conducted in specific parts of Africa in which HBV mixed-genotype infections are predominant [42]. The observed HBV mixed- genotypes infection in this study may be due to possible recombination between genotypes or migration flows. Therefore, the high prevalence of genotype $D$ in the population of Eritrea should raise concern.

The pattern of genotype distribution observed in this study is supported by several studies from Sudan $[43,44]$ and Côte d'Ivoire [36] using the same research methods. For instance, genotype $D$ is the dominant genotype in Northern Africa, Mediterranean and Middle East regions [29, 45, 46]. Comparatively, genotype $\mathrm{E}$, the second prevalence HBV mono-genotype in our study, is the most recent genotype originating in Africa and highly prevalence in Western and Central Africa $[34,36]$. The prevalence of genotype $D$ and $E$ in Eritrea (Table 1) may be explained by the fact that the country is in close proximity to Central Africa where genotype $E$ prevails, while genotype $E$ is prevalent in North Africa and the Middle East. Our result also indicated that the presence of genotype A, which is dominant in East Africa, was also significant.

Among mono-HBV genotypes infection distributed in Eritrea as reported in this study, genotype D was predominant in Maekel (42.9\%), Debub (60.9\%), Semienawi Keiyh Bahri (66.7\%), Gash Barka (60\%) and Anseba (75.5\%). Geographical distribution of HBV genotypes may play an important role in the extent of viral transmission. For example, genotypes $B$ and $C$ are more common in endemic regions of perinatal or vertical exposure, while genotypes $A, D$ and $E$ are primarily observed in regions of horizontal exposure [47]. Differences in natural history and, possibly, a different response to antiviral treatment may also explain the observed disparity [48]. Regarding this issue, some investigators have noted in SSA that the predominant HBV transmission route is horizontal and high probability of acquiring the infection during earlier childhood. Besides, differences in the distribution of HBV mixed-genotype infections were also observed. In fact, HBV mixed-genotype infection has been reported in disparate parts of the world [44, 49, 50]. However, the implication of the observed results is hard to uncover and may be subject to a range of biases and confounding factors, including the fact that most of the blood processed in this facility are from Zoba Maekel, differences in population densities and socio-cultural differences of attitudes towards blood donations across six regions. Overall, the regional variations in the distribution of mono-HBV and mixed-HBV genotypes has been observed by researchers in other regions [51-53].

\section{Conclusion}

In summary, the current study demonstrated a relatively low HBeAg positivity among blood donors. Genotype D is the predominant circulating genotype, either as a HBV mono- or mixed-genotypes infection, among blood donors across six Zoba regions in Eritrea. Therefore, this study has provided an insight in narrowing the existing knowledge gap of HBV molecular epidemiology in Eritrea and can be used as a 
reference for similar studies worldwide. Future studies should evaluate the relationships between clinical relevance of specific genotypes and treatment response, as well as programmatic and/or opportunistic screening for HBV in the general population. Effective education on HBV transmission control, antiviral treatment and vaccination should also be implemented.

\section{Future perspective}

This study represents the first attempt to present data on the serological and genotypical characteristics of HBV isolates among blood donors in Eritrea. Multiplex-nested PCR method is a useful tool for prediction of HBV genotypes in Eritrea, providing a simple tool for laboratories to screen the circulating genotypes. Nevertheless, some limitations in the current study are worth mentioning. It is known that all HBV isolates were obtained from 'healthy' individuals in blood donor settings, and HBV screening was done for safe blood transfusion. Therefore, future studies should explore the clinical settings with patients if the situation is different to further disease management. Sequencing studies are also needed for further HBV genotypes and sub-genotype confirmation. Additional large-scale studies are required as genotype $\mathrm{D}$ is more common in horizontal rather than vertical transmission.

\section{Summary Points}

- Hepatitis B virus (HBV) is highly endemic in sub-Saharan African, including Eritrea.

- HBV genotypes have distinct geographical distributions in Africa that affect the course of infection, clinical outcome and treatment efficacy.

- However, the information about HBV genotype distribution and prevalence in Eritrea is still elusive.

- This study aimed to determine serological markers and genotypes profiles of HBV isolates in Central Eritrea.

- Cross-sectional, laboratory-based study recruited 23,232 screened blood donors from 2015 to 2017, with $191 \mathrm{HBsAg}$ sero-positive samples were randomly selected for the study.

- Enzyme-linked immunosorbent assay was used to perform HBV serological markers screening, while genotypes were determined using type-specific primer-based multiplex-nested PCR.

- The median age of infected blood donors was $9 \pm 10.26$ years.

- Of $191 \mathrm{HBsAg}$ reactive serum samples, 5\% (148/191) were sero-positive for HBcAb-total, among which 99.3\% (147/148) and 0.7\% (1/148) were sero-positive for HBsAg and HBsAb, respectively.

- Interestingly, among $147 \mathrm{HBcAb}$-total/HBsAg reactive samples, 16 (10.9\%) and 131 (77.9\%) were sero-positive for HBeAg and HBeAb, respectively.

- For genotyping, 73 HBV isolates were successfully amplified and genotyped, with 59 (80.8\%) had a mono-genotype and 14 (19.2\%) had a mixed-genotype infection.

- Among $60 \mathrm{HBV}$ isolates with mono-genotypes, genotype $D$ was predominant $(n=39 ; 53.4 \%)$, followed by genotype $E(n=10 ; 13.7 \%)$, genotype $A(n=6,8.2 \%)$ and genotype $C(n=4 ; 5 \%)$. 
- While five mixed-genotypes comprised genotype C/D ( $n=6,8.2 \%)$, genotype C/D/E $(n=3 ; 1 \%)$, genotype $A / D$ and genotype $D / E$ (each with $n=2 ; 2.7 \%)$ and genotype $B / D(n=1 ; 1.4 \%)$.

- HBV genotype $D$ is the predominant genotype, either as a HBV mono- or mixed-genotype infection, among blood donors in Eritrea.

- This study enhances the understanding of genotype prevalence and improves the knowledge on HBV molecular studiesin Eritrea.

- Population-based studies with sequencing of HBV genotypes are recommended for further confirmation.

\section{Declarations}

Financial and competing interests disclosure

The authors have no relevant affiliations or financial involvement with any organization or entity with a financial interest in or financial conflict with the subject matter or materials discussed in the manuscript. This includes employment, consultancies, honoraria, stock ownership or options, expert testimony, grants or patents received or pending, or royalties. No writing assistance was utilized in the production of this manuscript.

Ethical conduct of research

Ethical approval was obtained from Orotta College of Medicine and Health Sciences (OCMHS) Research Ethical Committee (Rf.No.:0041/08/206) and Eritrean Ministry of Health Research Ethical Committee (Approval Number.:15/41/554/17). The authors have followed the principles outlined in the Declaration of Helsinki for all human or animal experimental investigations. The blood donors were anonymised during data collection and retrieving process, and codes were used to ensure their confidentiality. In this study, the informed consent was not required and waived by Eritrean Ministry of Health Research Ethical Committee. This procedure was undertaken exclusively by a data specialist from NBTS.

\section{Availability of data and materials}

All relevant data are available from the corresponding author on reasonable request.

\section{Acknowledgements}

The authors would like to thank the members of the Immunoserology Department at Eritrean National Health Laboratory and members of NBTS for assisting in the extraction of data from NBTS database, Eritrean National Council for Higher Education, and National Animal and Plant Health Laboratory.

\section{Abbreviations}


DKB: Debubawi Keiyh Bahri (Southern Red Sea); DNA: Deoxyribonuclease; ELISA: Enzyme-linked immunosorbent assay; HBcAb: Hepatitis B core antibody; HBeAb: Hepatitis B e antibody; HBeAg: Hepatitis B e antigen; HBsAb: hepatitis B surface antibody; HBsAg: Hepatitis B surface antigen; HBV: Hepatitis B virus; IQR: Interquartile range; M: Mean; Max: Maximum; Md: Median; Min: Minimum; NBTS: National Blood Transfusion Service; PCR: Polymerase chain reaction; SD: Standard deviation; SKB: Semienawi Keiyh Bahri (Northern Red Sea); SSA: Sub-Saharan Africa; TTI: Transfusion Transmissible Infections

\section{References}

1. Schweitzer A, Horn J, Mikolajczyk RT, Krause G, Ott JJ. Estimations of worldwide prevalence of chronic hepatitis B virus infection: a systematic review of data published between 1965 and 2013. The Lancet 386(10003), 1546-1555 (2015).

2. Kramvis A, Kew MC. Epidemiology of hepatitis B virus in Africa, its genotypes and clinical associations of genotypes. Hepatology research : the official journal of the Japan Society of Hepatology 37(s1), S9-s19 (2007).

3. Organization WH. Guidelines for the prevention care and treatment of persons with chronic hepatitis B infection: Mar-15. World Health Organization, (2015).

4. Blum HE. History and global burden of viral hepatitis.Digestive Diseases 34(4), 293-302 (2016).

5. Organization WH. WHO guidelines on hepatitis B and C testing. World Health Organization, (2017).

6. Jayaraman S, Chalabi Z, Perel P, Guerriero C, Roberts I. The risk of transfusion-transmitted infections in sub-Saharan Africa. Transfusion 50(2), 433-442 (2010).

7. Siraj $\mathrm{N}$, Achila OO, Issac $\mathrm{J}$ et al. Seroprevalence of transfusion-transmissible infections among blood donors at National Blood Transfusion Service, Eritrea: a seven-year retrospective study.BMC infectious diseases 18(1), 264 (2018).

8. Keleta YT, Achila OO, Haile AW et al. Seroprevalence of transfusion transmitted infections among blood donors in Gash Barka Zonal Blood Transfusion Center, Barentu, Eritrea, 2014 through 2017.BMC hematology 19(1), 5 (2019).

9. Valsamakis A. Molecular testing in the diagnosis and management of chronic hepatitis B.Clinical microbiology reviews 20(3), 426-439 (2007).

10. Feitelson MA, Larkin JD. New animal models of hepatitis B and C.ILAR journal 42(2), 127-138 (2001).

11. Barbini L, Elizalde M, Torres $C$, Campos R. Molecular epidemiology and genetic diversity of hepatitis B virus in Mar del Plata city, Argentina.Infection, Genetics and Evolution 19 152-163 (2013).

12. Kao J-H. Molecular epidemiology of hepatitis B virus. The Korean journal of internal medicine 26(3), 255 (2011).

13. Bartholomeusz A, Schaefer S. Hepatitis B virus genotypes: comparison of genotyping methods. Reviews in medical virology 14(1), 3-16 (2004).

14. Guirgis BS, Abbas RO, Azzazy HM. Hepatitis B virus genotyping: current methods and clinical implications. International Journal of Infectious Diseases 14(11), e941-e953 (2010). 
15. Kidd-Ljunggren K, Miyakawa Y, Kidd AH. Genetic variability in hepatitis B viruses. Journal of General Virology 83(6), 1267-1280 (2002).

16. Norder $\mathrm{H}$, Couroucé A-M, Magnius LO. Complete genomes, phylogenetic relatedness, and structural proteins of six strains of the hepatitis B virus, four of which represent two new genotypes. Virology 198(2), 489-503 (1994).

17. Stuyver L, De Gendt S, Van Geyt C et al. A new genotype of hepatitis B virus: complete genome and phylogenetic relatedness. Journal of general virology 81(1), 67-74 (2000).

18. Arauz-Ruiz P, Norder H, Robertson BH, Magnius LO. Genotype H: a new Amerindian genotype of hepatitis $B$ virus revealed in Central AmericaThe sequences reported in this paper will appear in the DDBJ/EMBL/GenBank databases under the accession numbers AY090452-61. Journal of general virology 83(8), 2059-2073 (2002).

19. Tatematsu $K$, Tanaka $Y$, Kurbanov $F$ et al. A genetic variant of hepatitis $B$ virus divergent from known human and ape genotypes isolated from a Japanese patient and provisionally assigned to new genotype J. Journal of virology 83(20), 10538-10547 (2009).

20. Fessehaye N, Naik D, Fessehaye T. Transfusion transmitted infections-A retrospective analysis from the National Blood Transfusion Service in Eritrea.Pan African Medical Journal 9(1), (2011).

21. Bertoni-Freddari C, Fattoretti P, Casoli T et al. Reactive structural dynamics of synaptic mitochondria in ischemic delayed neuronal death.Annals of the New York Academy of Sciences 1090 26-34 (2006).

22. Naito $H$, Hayashi $S$, Abe K. Rapid and specific genotyping system for hepatitis $B$ virus corresponding to six major genotypes by PCR using type-specific primers. Journal of clinical microbiology 39(1), 362-364 (2001).

23. Eko Mba JM, Bisseye $C$, Ntsame Ndong JM et al. Prevalent hepatitis B surface antigen among firsttime blood donors in Gabon.PloS one 13(4), e0194285 (2018).

24. Hussein NR, Haj SM, Almizori LA, Taha AA. The prevalence of hepatitis B and C viruses among blood donors attending blood bank in Duhok, Kurdistan region, Iraq.Int J Infect 4(1), e39008 (2017).

25. Wasfi $O$, Sadek N. Prevalence of hepatitis B surface antigen and hepatitis $C$ virus antibodies among blood donors in Alexandria, Egypt.EMHJ-Eastern Mediterranean Health Journal, 17 (3), 238-242, 2011 (2011).

26. Lau GKK. How do we handle the anti-HBc positive patient? (in highly endemic settings). Clinical liver disease 5(2), 29-31 (2015).

27. Fessehaye $N$, Berhane $A$, Ahimed $H$. Prevalence of hepatitis $B$ virus infection and associated seromarkers among pregnant women in Eritrea.Journal of Human Virology \& Retrovirology 6(1), 3038 (2018).

28. Ambachew H, Zheng M, Pappoe F, Shen J, Xu Y. Genotyping and sero-virological characterization of hepatitis B virus (HBV) in blood donors, Southern Ethiopia. 13(2), e0193177 (2018).

29. Habil FE, Mahdi WK, Abdelwahab SF, Abdel-Hamid M. Hepatitis B virus genotype D predominates HBsAg-positive egyptian blood donors and is mainly associated with a negative $\mathrm{HBeAg}$ serostatus. Intervirology 56(5), 278-283 (2013). 
30. Hasegawa I, Tanaka Y, Kurbanov F et al. Molecular epidemiology of hepatitis B virus in the United Republic of Tanzania. Journal of medical virology 78(8), 1035-1042 (2006).

31. Bárcena Marugán R, García Garzón S. DNA-guided hepatitis B treatment, viral load is essential, but not sufficient. World journal of gastroenterology 15(4), 423-430 (2009).

32. Hadziyannis SJ, Vassilopoulos D. Immunopathogenesis of hepatitis $B$ e antigen negative chronic hepatitis B infection.Antiviral research 52(2), 91-98 (2001).

33. Alzahrani FM, Shaikh SS, Alomar Al, Acharya S, Elhadi N. Prevalence of Hepatitis B Virus (HBV) Among Blood Donors in Eastern Saudi Arabia: Results From a Five-Year Retrospective Study of HBV Seromarkers.Annals of laboratory medicine 39(1), 81-85 (2019).

34. Valente F, Lago BVD, Castro CaVD, Almeida AJD, Gomes SA, Soares CC. Epidemiology and molecular characterization of hepatitis B virus in Luanda, Angola.Memórias do Instituto Oswaldo Cruz 105(8), 970-977 (2010).

35. Al-Suraifi ASK, Al-Rubaie ADJ, Al-Mayahie SMG, Al-Abedy NMM. Unusual HBV mixed genotype infections among hepatitis type b Iraqi patients in Wasit province/Iraq. Int J Biomed Eng Clin Sci 2 1-7 (2016).

36. Doumbia M, Kouassi M, Kakou N, Sevede D. Molecular characterization of hepatitis B virus isolated from two groups of patients at risk in Côte d'Ivoire.J Microbiol Res Rev 1 61-66 (2013).

37. Pandey P, Tiwari AK, Dara RC, Aggarwal G, Rawat G, Raina V. A comprehensive serological and supplemental evaluation of hepatitis B "seroyield" blood donors: A cross-sectional study from a tertiary healthcare center in India.Asian journal of transfusion science 9(2), 189 (2015).

38. Prabina P, Jayanthi S, Murthy CK et al. A study on hepatitis B viral seromarkers and associated risk factors among the patients suffering from acute and chronic hepatitis B infection.International Journal of Applied and Basic Medical Research 9(4), 206 (2019).

39. Al-Rubaye A, Tariq Z, Alrubaiy L. Prevalence of hepatitis B seromarkers and hepatitis $C$ antibodies in blood donors in Basra, Iraq.BMJ open gastroenterology 3(1), (2016).

40. Wang Z, Zeng J, Li T et al. Prevalence of hepatitis B surface antigen (HBsAg) in a blood donor population born prior to and after implementation of universal HBV vaccination in Shenzhen, China. BMC infectious diseases 16(1), 498 (2016).

41. Khaled laEA, Mahmoud OM, Saleh AF, Bioumie EE. Prevalence of HBV genotypes among Egyptian hepatitis patients. Molecular biology reports 38(7), 4353-4357 (2011).

42. Ahmad AE, Bakari AG, Musa BOP et al. Pattern of prevalent hepatitis B virus genotypes in Zaria, Nigeria. The Nigerian postgraduate medical journal 26(2), 80 (2019).

43. Enan KA, Minosse $C$, El Hussein ARM et al. Analysis of hepatitis B virus-mixed genotype infection by ultra deep pyrosequencing in Sudanese patients, 2015-2016.Infection 47(5), 793-803 (2019).

44. Salih EY, Saeed WSE, Satti MMH, Abbas G, Suleiman IA, Khalil EaG. Hepatitis B virus genotypic patterns in Sudan reflects population movements. (2017). 
45. Yousif M, Mudawi H, Hussein W et al. Genotyping and virological characteristics of hepatitis B virus in HIV-infected individuals in Sudan. International Journal of Infectious Diseases 29 125-132 (2014).

46. Yousif M, Mudawi H, Bakhiet S, Glebe D, Kramvis A. Molecular characterization of hepatitis $B$ virus in liver disease patients and asymptomatic carriers of the virus in Sudan.BMC infectious diseases 13(1), 328 (2013).

47. Kyaw YY, Lwin AA, Aye KS et al. Distribution of hepatitis $B$ virus genotypes in general population of Myanmar via Nation wide study. (2020).

48. Palumbo E, Scotto G, Faleo G, Cibelli DC, Saracino A, Angarano G. Prevalence of HBV-genotypes in immigrants affected by HBV-related chronic active hepatitis.Arquivos de gastroenterologia 44(1), 5457 (2007).

49. Rahman MA, Hakim F, Ahmed M, Ahsan CR, Nessa J, Yasmin M. Prevalence of genotypes and subtypes of hepatitis B viruses in Bangladeshi population.SpringerPlus 5(1), 278 (2016).

50. Bokharaei-Salim F, Keyvani H, Monavari SH et al. Distribution of hepatitis B virus genotypes in azerbaijani patients with chronic hepatitis B infection. Hepatitis monthly 14(12), (2014).

51. Nie J-J, Sun K-X, Li J et al. A type-specific nested PCR assay established and applied for investigation of HBV genotype and subgenotype in Chinese patients with chronic HBV infection. Virology journal 9(1), 121 (2012).

52. Zhao Y, Zhang X-Y, Guo J-J et al. Simultaneous genotyping and quantification of hepatitis $B$ virus for genotypes B and C by real-time PCR assay.Journal of clinical microbiology 48(10), 3690-3697 (2010).

53. Al Baqlani SA, Sy BT, Ratsch BA et al. Molecular epidemiology and genotyping of hepatitis B virus of HBsAg-positive patients in Oman.PloS one 9(5), e97759 (2014).

\section{Figures}




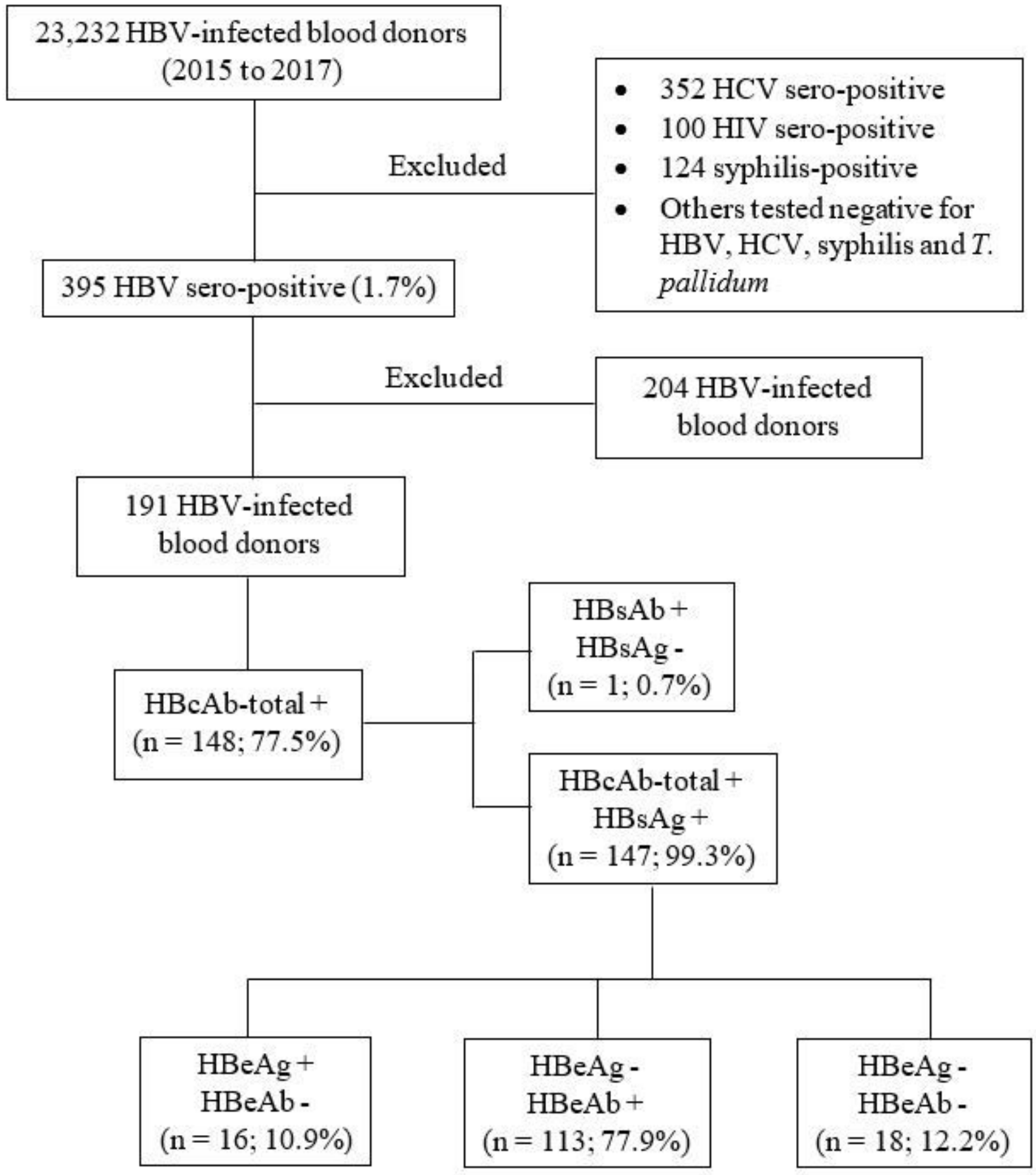

Figure 1

Cumulative results of HBV serological markers among blood donors recruited from NBTS, Asmara, Eritrea. 


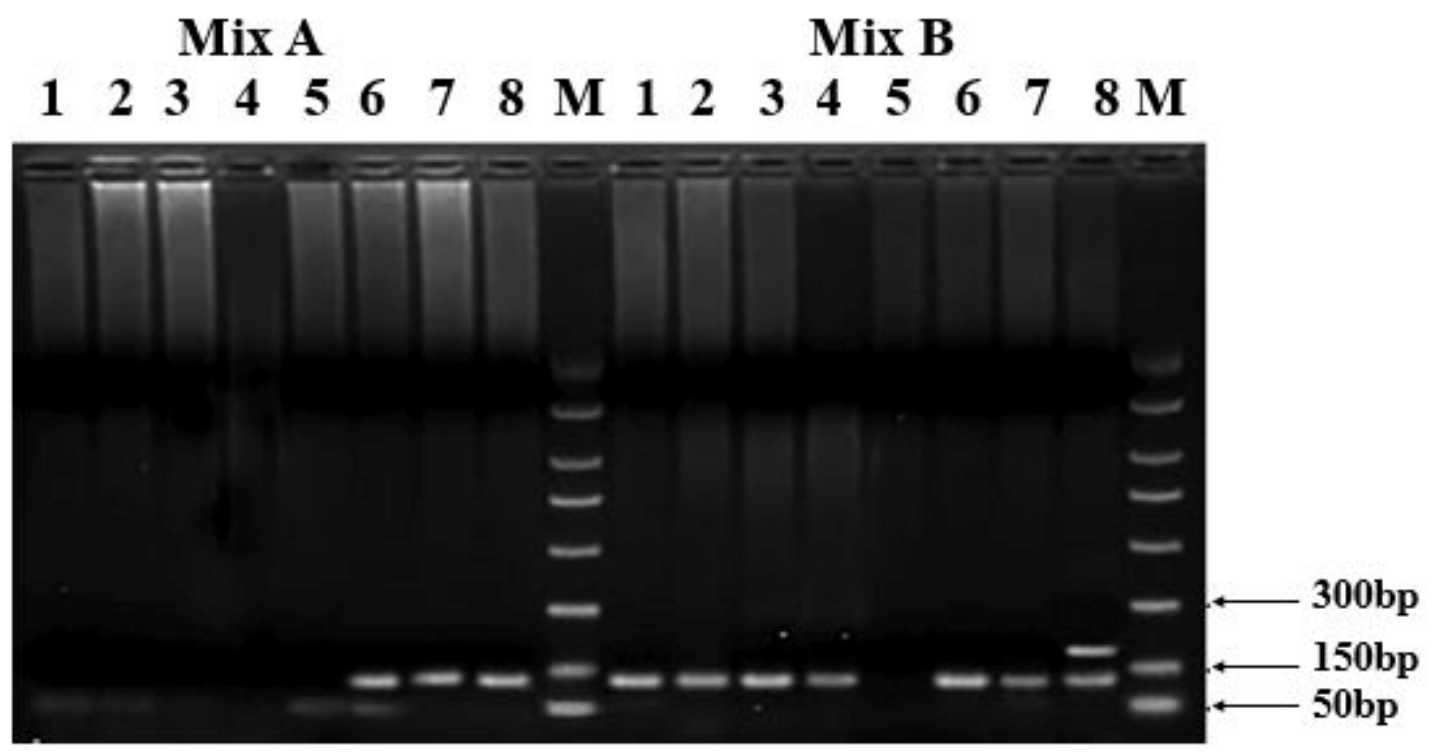

Figure 2

Second PCR products showing single HBV genotype D (119 bp) in lanes 1,2,3,4, mixed genotypes C (122 bp) and D (119) in line 6 and 7, and genotypes C (122 bp), D (119) and E (167 bp) in lane 8. Lanes 5 showing negative genotype, (Full gel image has been provided). M, molecular size standards; $50-2,000$ bp DNA ladder (Sigma-Aldrich, USA).

Mix A

Mix B

\section{$\begin{array}{llllllllllllllllll}1 & 2 & 3 & 4 & 5 & 6 & 7 & 8 & M & 1 & 2 & 3 & 4 & 5 & 6 & 7 & 8 & M\end{array}$}

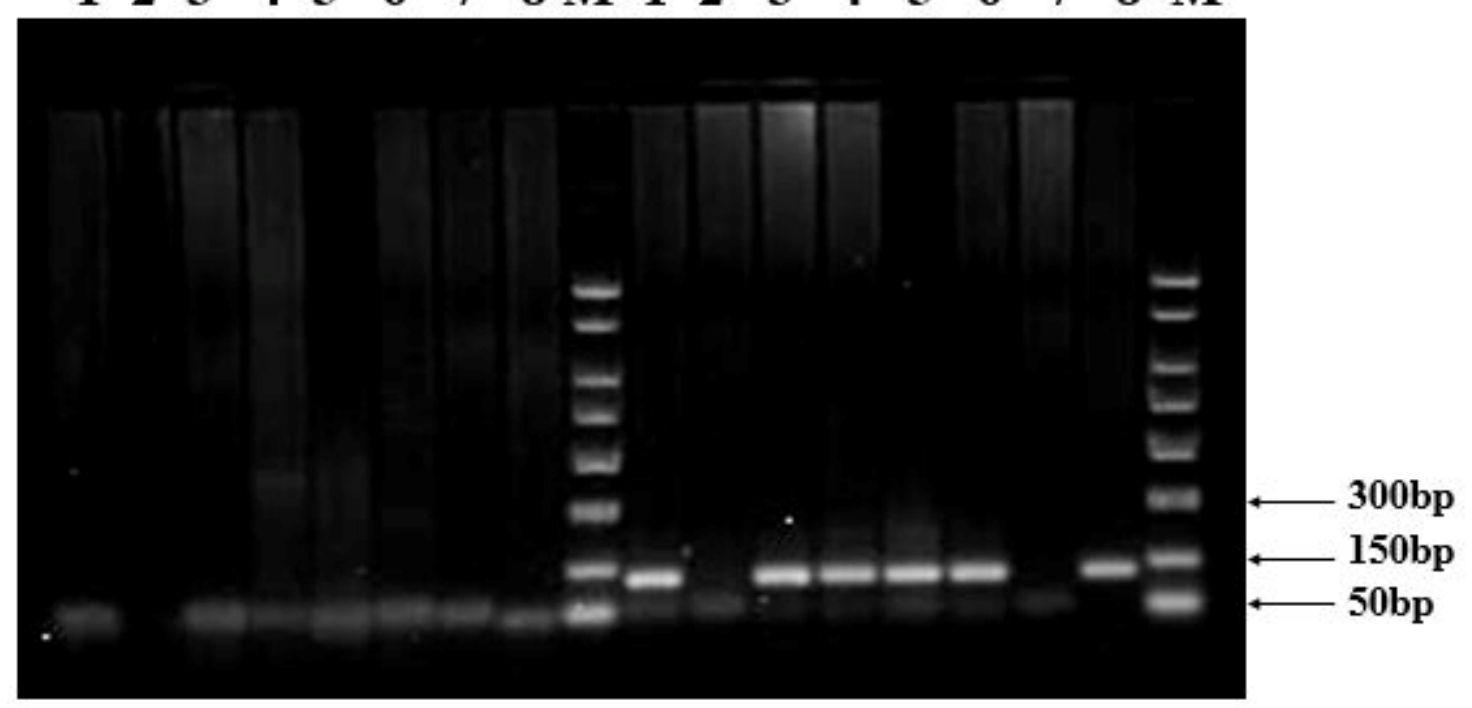

Figure 3

Second PCR products showing single HBV genotype D (119 bp) in lanes 1,3,4, 5, 6 and 8 . Lanes 2 and 7 showing negative genotype, (Full gel image has been provided). $M$, molecular size standards; 50-2,000 bp DNA ladder (Sigma-Aldrich, USA). 